\title{
Water risk assessment in China based on the improved Water Risk Filter
}

\author{
GAN HONG ${ }^{1,2}$, QIU YAQIN ${ }^{1,2}$, LU QIONG $^{2}$, NIU CUNWEN ${ }^{2}$, WEI NA ${ }^{2}$, \\ LIU JIAJIA ${ }^{2}$, GAN YONGDE ${ }^{2}$, ZHOU NA ${ }^{2}$ \& DING XIANGYI ${ }^{2}$ \\ 1 State Key Laboratory of Simulation and Regulation of Water Cycle in River Basin, China Institute of Water Resources \\ and Hydropower Research, 100038, China \\ ganhong@iwhr.com, qyqiwhr@126.com, lq iwhr@163.com \\ 2 Department of Water Resources, China Institute of Water Resources and Hydropower Research, 100038, China
}

\begin{abstract}
Finding an effective way to deal with the water crisis and the relationship between water and development is a major issue for all levels of government and different economic sectors across the world. Scientific understanding of water risk is the basis for achieving a scientific relationship between water and development, and water risk assessment is currently an important research focus. To effectively deal with the global water crisis, the World Wide Fund for Nature and German Investment and Development Company Limited proposed the concept of water risk and released an online Water Risk Filter in March 2012, which has been applied to at least 85 countries. To comprehensively and accurately reflect the situation of water risk in China, this study adjusts the water risk assessment indicators in the Water Risk Filter, taking the actual situation in China and the difficulty of obtaining the information about the indicators into account, and proposes an index system for water risk evaluation for China which consists of physical risk, regulatory risk and reputational risk. The improved Water Risk Filter is further used to assess the sources and causes of the water risks in 10 first-class and seven second-class water resource areas (WRAs). The results indicate that the water risk for the whole country is generally medium and low, while those for different regions in the country vary greatly, and those for southern regions are generally lower than those for northern regions. Government regulatory and policy implementation as well as media supervision in northern regions should be strengthened to reduce the water risk. The research results may provide decision support and references for both governments and industrial enterprises in identifying water risks, formulating prevention and control policies, and improving water resources management in China.
\end{abstract}

Key words water risk assessment; water risk filter; assessment method

\section{INTRODUCTION}

The excessive and disorderly development of water resources comes with environmental and ecological problems. These problems impact on the sustainable development of economic society and the ecological balance of the system. Currently, the water resources situation in China is not optimistic. Water shortage, water pollution and other problems have occurred in the last few decades. Both the quantity and quality of water are confronting crises. Such crises are an unavoidable challenge for water-scarce countries, including China. To deal with these water resource problems, implementing risk management of water resources is effective and a developing trend for improving water resources management skills and reactions to problems. These are topical issues for not only academia, but also communities to discuss and decide how to make water risk assessments scientifically, and what kind of development would be better for sustainable use and ecological protection of water resources.

The World Wide Fund for Nature (WWF) and German Investment and Development Company Ltd (DEG), has launched a Water Risk Assessment methodology (http://waterriskfilter.panda.org/). It is an index system for Water Risk Assessment that works at the state, basin and enterprise levels. This assessment has been done for 85 countries, 22 basins and nearly 25000 enterprises, with some results published online. The original purpose was to quantitatively measure the impact on water bodies, the water environment and water ecology during the development of an economic entity (nation or region). These quantitative measurements include nature, society (e.g. developing laws and regulations, enforcement and regulation of water pollution and macro-decision-making) and economic activities (e.g. intake, usage and discharge of water). It refers to natural factors and human activities that cause potential risks associated with water including physical, regulatory and reputational risks. It also provides support for macro-decision-making by government and enterprises. This article uses the Water Risk Filter as a priority method with local adjustments, to estimate the basin-scale water risk for the ten water regions and seven sub-regions in China. 


\section{WATER RISK ASSESSMENT METHOD FOR BASINS IN CHINA}

WWF proposes 19 indicators for the Water Risk Assessment for basins; 12 are physical risk indicators, four are regulatory risk indicators and three are reputational risk indicators. Together the indicators characterize water risk from the water quantity, quality, hydropower and ecological environment perspective. They also take the effects of the development of economic society and water management into account. Government functions and public opinion are also considered in the assessment. Taking into consideration the water features and statistics of China, the WWF Water Risk Filter has been adjusted for the country.

\section{Selection of assessment indicators}

The selection of Water Risk Assessment indicators is guided by the following principles: (1) The main factors that can affect water risk, including nature, economy, society, culture, institution building and public supervision. (2) The indicators can be calculated quantitatively. Most of the indicators are recognized more internationally, such as the environmental vulnerability index (EVI) of the South Pacific Applied Geosciences Commission, and the Blue Water Shortage Rate of the Water Footprint Network, etc. (3) Indicators should be applicable in most nations or regions. They can represent actual conditions and have been widely accepted by nations and regions. In general, the above principles are very necessary to reflect the objectivity and rationality of the calculation result. They are also very useful for reflecting differences between countries.

However, in selecting many of the Water Risk Assessment indicators, most were chosen from the research results of international organizations and the developed countries and areas, and some are inconsistent with the statistical system in China. Due to technical conditions, many indicators are not included in the regular Chinese statistics. Take EVI as an example: EVI involves a mining indicator, oil spills indicator and conflicts indicator, and shows the impact of socio-economic activities on ecology. These indicators are not listed in the regular national statistics system in China. Thus, the research team adjusted the Water Risk Filter indicator system to better reflect the current situation in China. The principles of the adjustment are to choose indicators in accordance with statistical practice to make the statistics measurable and quantifiable. The adjusted indicator concepts are similar to the WWF ones, and allow comparison of the result among countries around the world. The major indicators adjusted are described below.

1. Given the difficulty of data collection, three indicators were deleted: "multi-year average monthly water shortage rate", "number of months is completely dry" and "maximum monthly water shortage rate". By using the multi-year average rate of water shortage, the water shortage level in a basin or region can determined. Water shortage rate is an indicator that can ensure water quantity. This refers to the level to which water demand is satisfied and the water security level of water supply in the current economic society. The water shortage rate is ratio of total demand to total available amount. The water shortage rate comprehensively reflects the relationship and degree of coordination between water resources and population, and in addition, between economic society and technological conditions.

2. The concepts of three indicators were redefined with simplified calculation methods including "effects of climate change", "vulnerability of water ecological system" and "water pollution discharge". Multi-year average annual temperature change is used as the metric basis for indicator of climate change. By calculating the average annual temperature change in a region, the level of climate change effects in the region can be acquired. The aridity index, in-stream ecological water usage ratio, ecological water shortage rate and groundwater overdraft rate are used for comprehensive evaluation of the water ecological safety situation instead of evaluation of EVI. Also, the water pollution situation is analysed by choosing wastewater discharge, pollutant discharge (COD and ammonia), sewage treatment indicator and circumstances of river body pollution.

3. The connotations of severe drought and great floods are redefined. Severe droughts mainly evaluate meteorological drought and analyse the occurrence range of drought and severe 
drought with a precipitation anomaly percentage no greater than $50 \%$. Great floods mainly analyse the return period of a basin-wide flood/great flood as no less than 20 years.

4. Under the reputational risk indicator category, two indicators "criticism report of possible water problems by local/national media" and "criticism report of possible water problems by national/global media" are combined into a single indicator as "criticism report of possible water problems by domestic media".

After adjustment, there are 16 indicators for China's water risk assessment (Wang Hao et al. 2013). Of these, 10 are physical risk assessment indicators, four relate to regulatory risk and two for reputational risk (Na Wei 2014). For the physical risk assessment indicator, the uneven spatial and temporal distribution of water resources and the frequency of extreme events, the contradiction between demand and supply, climate change and other aspects can reflect the water scarcity situation. This includes the four indexes of "multi-year average annual water shortage level", "effects of climate change", "impact range of severe drought" and "frequency of great flood" (during 19852005). It also reflects the ecosystem health with regard to the water sources condition (biodiversity, safety of water ecology and safe drinking water) and pollutant sources. This also includes four other indexes of "freshwater biodiversity threat", "water ecological security", "safe drinking water penetration" and "lavatories penetration". For the regulatory risk assessment indicator, the strategic planning of the government, construction of the legal system and extent of public participation are the indexes. The reputational risk assessment can be determined from the local development of water culture and public opinion.

After the adjustment of China's Water Risk Assessment indicators, it has similar concepts to those of WWF. For example, the multi-year average annual water shortage level in China's Water Risk Assessment indicator and the multi-year average water shortage rate from the WWF both reflect the water shortage condition. This is influenced by water resources endowments, socioeconomic development and many other indexes. The water pollution condition indicator means both China and WWF reflect the pollutant discharge situation that has direct or indirect negative impacts on water resources and biodiversity. The water ecological security situation and EVI are a reflection of disturbance of water ecology by climate change and human activities.

\section{Setting of the Percentage Weight}

The Water Risk Assessment has given a Percentage Weight to each indicator. Physical risk takes $55 \%$ of the total, leaving $35 \%$ for regulatory risk and $10 \%$ for reputational risk. There is no Percentage Weight for the subcategories of each risk as yet (Note: the Percentage Weight used here refers to that determined by WWF in 2012; this Percentage Weight system is still under modification). Basically, the physical risk, regulatory risk and reputational risk are multiplied by the Percentage Weight of each subcategory and the Percentage Weight of each risk. In this method, 19 indicators can be calculated by the percentage referring to water risk as shown in Table 1. There are six indicators with Percentage Weights greater than 8\%: "water pollution condition", "complexity and transparency of water-related laws and regulations system", "water issues discussed by stakeholders in official forum or platform", "implement of water-related laws and regulations", "multi-year average monthly water shortage rate" and "number of months is completely dry", etc. Of these indicators, "water pollution condition" has a Percentage Weight of $13.8 \%$ and four have Percentage Weights less than 2\% ("vulnerability of water ecological system", "safe drinking water penetration", "lavatories penetration" and "hydropower dependence"). The "vulnerability of water ecological system" indicator takes only $0.7 \%$. The Percentage Weight is set for world problems that common occur in water resources development and utilization.

Percentage Weights also provide fine-adjustment for the China Water Risk Assessment indicators. Each of the categories and sub-categories retain the same values as the original Percentage Weight system. But, the weights for both "maximum water shortage rate" and "number of month is completely dry" are redistributed to the indicator of "multi-year average annual water shortage level" (Table 1). Also, the original Percentage Weight of both "criticism report of possible water problems by local/national media" and "criticism report of possible water problems 
Table 1 Percentage weight of water risk assessment indicator.

\begin{tabular}{|c|c|c|c|c|}
\hline Category & $\begin{array}{l}\text { WWF Water Risk Assessment Indicator } \\
\text { Indicator }\end{array}$ & Weight $(\%)$ & $\begin{array}{l}\text { China Water Risk Assessment Indicator } \\
\text { Indicator }\end{array}$ & $\begin{array}{l}\text { Weight } \\
(\%)\end{array}$ \\
\hline \multirow[t]{12}{*}{$\begin{array}{l}\text { Physical } \\
\text { risk }\end{array}$} & $\begin{array}{l}\text { Multi-year average monthly water } \\
\text { shortage rate (water footprint) }\end{array}$ & 8.25 & $\begin{array}{l}\text { Multi-year average annual water } \\
\text { shortage level (blue water) }\end{array}$ & 16.50 \\
\hline & Number of month is completely dry & 8.25 & -- & -- \\
\hline & Maximum water shortage level & 6.60 & -- & -- \\
\hline & Climate change impact & 3.30 & Climate change impact & 3.30 \\
\hline & Impact range of severe drought & 3.30 & Impact range of severe drought & 6.60 \\
\hline & $\begin{array}{l}\text { Frequency of great flood (1985- } \\
2005)\end{array}$ & 3.30 & $\begin{array}{l}\text { Frequency of great flood (1985- } \\
2005)\end{array}$ & 6.60 \\
\hline & Water pollution condition & 13.75 & Water pollution condition & 13.75 \\
\hline & Freshwater biodiversity threat & 3.44 & Freshwater biodiversity threat & 3.44 \\
\hline & $\begin{array}{l}\text { Water environmental vulnerability } \\
\text { index }\end{array}$ & 0.69 & $\begin{array}{l}\text { Water environmental vulnerability } \\
\text { index }\end{array}$ & 0.69 \\
\hline & Safe drinking water penetration & 1.38 & Safe drinking water penetration & 1.38 \\
\hline & Lavatory penetration & 1.38 & Lavatory penetration & 1.38 \\
\hline & Hydropower dependence & 1.38 & Hydropower dependence & 1.38 \\
\hline \multirow[t]{4}{*}{$\begin{array}{l}\text { Regulat- } \\
\text { ory risk }\end{array}$} & $\begin{array}{l}\text { Water strategy of government (local, } \\
\text { national and upstream) }\end{array}$ & 7.00 & $\begin{array}{l}\text { Water strategy of government (local, } \\
\text { national and upstream) }\end{array}$ & 7.00 \\
\hline & $\begin{array}{l}\text { complexity and transparency of water- } \\
\text { related laws and regulations system }\end{array}$ & 10.50 & $\begin{array}{l}\text { complexity and transparency of water- } \\
\text { related laws and regulations system }\end{array}$ & 10.50 \\
\hline & $\begin{array}{l}\text { implement of water-related laws and } \\
\text { regulations }\end{array}$ & 8.75 & $\begin{array}{l}\text { implement of water-related laws and } \\
\text { regulations }\end{array}$ & 8.75 \\
\hline & $\begin{array}{l}\text { water issues discussed by stakeholders } \\
\text { in official forum or platform }\end{array}$ & 8.75 & $\begin{array}{l}\text { water issues discussed by stakeholders } \\
\text { in official forum or platform }\end{array}$ & 8.75 \\
\hline \multirow[t]{3}{*}{$\begin{array}{l}\text { Reputat- } \\
\text { ional risk }\end{array}$} & $\begin{array}{l}\text { Importance of water in local culture } \\
\text { and/or religion }\end{array}$ & 1.50 & $\begin{array}{l}\text { Importance of water in local culture } \\
\text { and/or religion }\end{array}$ & 1.50 \\
\hline & $\begin{array}{l}\text { criticism report of possible water } \\
\text { problems by local/national media }\end{array}$ & 4.50 & $\begin{array}{l}\text { criticism report of possible water } \\
\text { problems by domestic media }\end{array}$ & 8.50 \\
\hline & $\begin{array}{l}\text { criticism report of possible water } \\
\text { problems by national/global media }\end{array}$ & 4.00 & & \\
\hline
\end{tabular}

by national/global media" are combined into "criticism report of possible water problems by domestic media". Thus, China's calculation result is comparable with that from other countries. See Table 1 for details for the Percentage Weights of the Water Risk Assessment indicators.

\section{RESULT OF CHINA'S WATER RISK ASSESSMENT}

Whole China water risk is in either low-risk areas or medium-risk areas China has 10 water regions (Table 2) and these are rated as grade II-III of water risk, i.e. low-risk or medium-risk areas. The five water regions in northern China are all medium-risk areas. The Haihe River has a much higher risk level. The four water regions in southern China are low-risk area, of which the Yangtze River is lower than the others. In the Yangtze River region, all sub-regions have grade II water risks.

Physical risks in southern China are generally lower than in northern China. From the view of physical risk, northern China is rated between grade II to IV; the Haihe River region has the highest risk, grade IV; the Songhua, Liaohe, Yellow and Huaihe river regions are all grade III. Rivers in Northwest China are grade II. Southern China river regions are grade II, i.e. have generally lower physical risk levels than in northern China.

Regulatory risk in China is graded low-risk or medium-risk After nearly 30 years of development, China has established a comparatively perfect law and regulation system for water in line with China's national and water conditions. Water management and utilization are gradually moving into the standardization and legalization track. The ability of water administration and management is being continuously enhanced. The rivers in the Northwest China are grade III regulatory risk, but the other nine water regions are grade II. But differences still exist between each water regions. The Yangtze and Yellow rivers have lower scores in their sub-regions. 
Table 2 Water risk assessment result.

\begin{tabular}{|c|c|c|c|c|c|c|c|c|c|c|c|}
\hline \multirow[t]{2}{*}{ CATEGORY/Indicator } & \multirow{2}{*}{$\begin{array}{l}\% \\
\text { Weight }\end{array}$} & \multicolumn{10}{|c|}{ Assessment result } \\
\hline & & $\begin{array}{l}\text { Songhua } \\
\text { River }\end{array}$ & $\begin{array}{l}\text { Liaohe } \\
\text { River }\end{array}$ & $\begin{array}{l}\text { Haihe } \\
\text { River }\end{array}$ & $\begin{array}{l}\text { Yellow } \\
\text { River }\end{array}$ & $\begin{array}{l}\text { Huaihe } \\
\text { River }\end{array}$ & $\begin{array}{l}\text { Yangtze } \\
\text { River }\end{array}$ & $\begin{array}{l}\text { Pearl } \\
\text { River }\end{array}$ & $\begin{array}{l}\text { Rivers } \\
\text { in SE } \\
\text { China }\end{array}$ & $\begin{array}{l}\text { Rivers } \\
\text { in SW } \\
\text { China }\end{array}$ & $\begin{array}{l}\text { Rivers } \\
\text { in NW } \\
\text { China }\end{array}$ \\
\hline PHYSICAL RISK & & 2.3 & 2.4 & 3.6 & 2.5 & 2.3 & 1.2 & 1.1 & 1.2 & 1.3 & 1.6 \\
\hline $\begin{array}{l}\text { Multi-year average annual water } \\
\text { shortage level (blue water) }\end{array}$ & 16.5 & 2.2 & 3.0 & 4.8 & 3.8 & 2.9 & 0.4 & 0.0 & 0.7 & 1.8 & 2.2 \\
\hline Climate change impact & 3.3 & 4.5 & 2.3 & 2.6 & 1.3 & 0.7 & 0.1 & 0.3 & 0.2 & 0.7 & 2.5 \\
\hline Impact range of severe drought & 6.6 & 1.1 & 1.1 & 1.0 & 1.0 & 1.0 & 1.0 & 1.0 & 1.0 & 1.1 & 1.4 \\
\hline Frequency of great flood (1985-2005) & 6.6 & 1.5 & 1.5 & 1.5 & 1.0 & 2.0 & 1.5 & 2.3 & 1.0 & 1.0 & 1.0 \\
\hline Water pollution condition & 13.8 & 2.4 & 2.5 & 5.0 & 2.4 & 2.4 & 1.3 & 1.0 & 1.1 & 0.0 & 0.2 \\
\hline Freshwater biodiversity threat & 3.4 & 4.3 & 4.4 & 4.5 & 4.5 & 4.7 & 4.2 & 4.4 & 4.5 & 3.7 & 3.8 \\
\hline Safe water ecology condition & 0.7 & 2.1 & 3.4 & 4.1 & 3.4 & 3.0 & 1.5 & 1.1 & 1.5 & 1.2 & 2.7 \\
\hline Safe drinking water penetration & 1.4 & 1.3 & 1.2 & 1.2 & 1.7 & 1.8 & 0.8 & 0.2 & 0.6 & 1.1 & 2.8 \\
\hline Lavatory penetration & 1.4 & 2.6 & 2.7 & 3.1 & 3.5 & 2.7 & 3.2 & 1.9 & 2.8 & 3.6 & 3.4 \\
\hline Hydropower dependence & 1.4 & 1.0 & 0.7 & 0.2 & 1.2 & 0.2 & 2.4 & 1.6 & 1.8 & 3.4 & 1.6 \\
\hline REGULATORY RISK & 1.8 & 1.8 & 1.5 & 1.3 & 1.4 & 1.1 & 1.4 & 1.8 & 2.0 & 2.1 & 1.8 \\
\hline Water strategy of government & 7.0 & 1.0 & 1.0 & 1.0 & 1.0 & 1.0 & 1.0 & 1.0 & 1.0 & 1.0 & 1.0 \\
\hline $\begin{array}{l}\text { Complexity and transparency of water- } \\
\text { related laws and regulations system }\end{array}$ & 10.5 & 1.0 & 1.0 & 1.0 & 1.0 & 1.0 & 1.0 & 1.0 & 1.0 & 1.0 & 1.0 \\
\hline $\begin{array}{l}\text { Implementation of water-related laws } \\
\text { and regulations }\end{array}$ & 8.8 & 3.0 & 3.3 & 2.2 & 2.3 & 1.5 & 1.3 & 1.7 & 2.2 & 3.0 & 3.3 \\
\hline $\begin{array}{l}\text { Water issues discussed by stakeholders } \\
\text { in official forum or platform }\end{array}$ & 8.8 & 2.0 & 2.0 & 2.0 & 1.0 & 2.0 & 1.0 & 2.0 & 3.0 & 3.0 & 3.0 \\
\hline REPUTATIONAL RISK & 2.4 & 3.4 & 3.4 & 2.7 & 3.3 & 3.3 & 3.4 & 3.4 & 1.8 & 1.6 & 2.4 \\
\hline $\begin{array}{l}\text { Importance of water in local culture } \\
\text { and/or religion }\end{array}$ & 1.5 & 5.0 & 5.0 & 5.0 & 5.0 & 5.0 & 5.0 & 5.0 & 5.0 & 5.0 & 5.0 \\
\hline $\begin{array}{l}\text { Criticism report of possible water } \\
\text { problems by domestic media }\end{array}$ & 8.5 & 1.9 & 3.1 & 3.1 & 2.3 & 3.1 & 3.0 & 3.1 & 3.1 & 1.3 & 1.0 \\
\hline Water Risk Assessment result & 2.1 & 2.3 & 2.9 & 2.1 & 2.1 & 1.4 & 1.4 & 1.6 & 1.6 & 1.8 & \\
\hline
\end{tabular}

Reputational risk is medium-risk or high-risk area in China Since the founding of New China, water control and water culture have been important parts of the management of state affairs and key concepts. China's main religions pay sufficient attention to water resources, water protection and water conservation. In addition, China's domestic media is able to report and expose issues related to water problems in a timely and objective way. This should initiate public attention to China's water problems and potential water risk. According to the reputational risk system, rivers in Northwest and Southwest China are grade II. Songhua River and Yellow River are grade III. The other seven water regions are grade IV.

\section{CONCLUSION}

The building of China's Water Risk Assessment system for basins is necessary to join the international evaluation system and make comparisons with other countries. It needs to take the national conditions into account, so that the assessment result is usable and reflects the real situation of different basins. The localized WWF Water Risk Filter has considered China's water features and statistical practices. It can quantitatively explain the relations between water risk and different factors such as natural climate, water resources development and exploitation, government regulation and social culture.

China has 10 water regions and seven sub-regions; the overall water risk is between grade II and III, i.e. low-risk to medium-risk. This assessment result coincides with the global risk assessment. In the much more objective physical risk assessment result, the northern China area (i.e. six water regions, the Songhua, Liaohe, Haihe, Yellow and Huaihe river regions and Rivers in Northeast China) are grade II to grade IV. Haihe River region has the highest grade, IV. Southern China (four water regions: Yangtze River, Rivers in Southeast China, Pearl River, and Rivers in Northwest China) are all grade II. This is generally lower than northern China. However, from the point view of different sub-regions, there are large spatial differences. For example, from upstream to downstream the water pollution status of the Yangtze River gradually gets worse. Taihu Lake has the worst status. 
The reason that China's overall water risk is lower is that the assessment result is based on a global scale. The natural water environment of China's densely populated areas is "innately" liveable with. Although 30 years of fast industrialization is increasingly generating a crisis for the water environment, the risks from the water pollution and water shortage aspects are just parts of the whole indicator system. Thus, by looking at the whole result from the Water Risk Filter, the conclusion that China's water risk is not high on a global range, is rational.

The Percentage Weight of indicators is designed for common problems that consider water resources development and exploitation and integrated management in different countries. In China, indicators with a high Percentage Weight have medium or low scores, and high scores occur for indicators with lower Percentage Weight. Thus, the calculated water risk for China is entirely in medium-risk or low-risk area. According to the assessment result by Vorosmarty et al. (2010), China's freshwater biodiversity threat risk scores high relative to the global range, whereas this indicator only has $3.44 \%$ for its Percentage Weight in this assessment. The water footprint network has published data for 139 countries and regions. Analysing these data shows that China has a $30 \%$ blue water shortage rate, and ranks at 70th by increasing order. This indicator's Percentage Weight is $16.5 \%$.

\section{Recommendations}

Although the use of the index system can reflect the relative differences between different water regions and the main factors affecting water risk, to the limits of the existing technology, the statistics situation, and methods for calculating the indicator assessment and understanding of it, there is still room for improving the Water Risk Assessment method. By identifying the inadequacies of this assessment, with future data improvement and collection, its practicality will be promoted. Specifically, improvements can be made as follows:

1. Add more indicators that can reflect regional characteristics. China has rich aquatic biodiversity and is facing stress to the water ecosystem with changes in risk. The assessment indicators should include ones that can show the variety of China's aquatic biodiversity; e.g. including porpoise as a key species for an indicator. Within the fast growing social economy of China, with its acceleration of population and urbanization growth, water requirements are increasing too. This causes disturbance to water resources by human activities, which is one of the main reasons that causes water risk. Therefore, socio-economic features of water usage and the trend of change itself should be added as a factor in the Water Risk Assessment indicator system. Although, China has accomplished considerable progress on water management, still many laws and regulations are imperfect. Also, there are many complex elements that can affect the regulatory and reputational risk. Thus, some strong representation and quantifiable indicators should be included.

2. Improve the calculation of relevant indicators. The water resource is a controlling element of ecological environment structure. It is the basic resource for maintaining a stable ecological environment. Socio-economic development should not be at the cost of the ecological environment, which is why a certain amount of water needs to be reserved for the ecological environment. The calculation of water shortage rate should considering coordinated development with the social economy and ecological environment. In recent years, pollutants have diversified in China and presented a feature of combined pollution. New pollutants appear that cause greater harm to China's water environment and water ecology. Consequently, the assessment indicators should be able to reflect discharge conditions for feature pollutants.

3. Select a reasonable spatial and temporal scale along with scoring criteria. China has a vast territory with complex and diverse climates and landscapes. Due to its geographic location, terrain and climate, floods occur frequently. Combining the high exploitation under huge population pressure and high risk area of flood, makes China one of the countries that have the highest flood frequency in the world. China is located in the Asian monsoon region but the terrain has fundamentally determined the frequent droughts. It is complex to objectively identify 
droughts and quantitatively assess their impact. Consequently, using reasonable spatial and temporal scales for identification and determination of water risk is very important.

4. Combining key industrial sectors risk sources and enterprise water risk with basin risk will achieve both macro-decision-making and micro-management of basins. It will enhance the practicality of the Water Risk Filter. This will provide advice for basin/region industrial layout adjustment and major strategic planning. In addition, it will offer support for decisions of the strictest water resource management.

Acknowledgement The research received financial support from the special fund project of public welfare of Ministry of Water Resources (201301001), the Nature Science Foundation of China (51021066, 50939006, 51209224), and the Project of State Key Laboratory of Simulation and Regulation of Water Cycle in River Basin (2013ZY02, 2013QN02).

\section{REFERENCES}

Wei, N., et al. (2014) Study on Water Risk Assessment in River Basins of China Based on WWF Water Risk Assessment Tools. Evolving Water Resources Systems: Understanding, Predicting and Managing Water-Society Interactions (Proceedings of ICWRS2014, Bologna, Italy, June 2014). IAHS Publ. 364, IAHS Press, Wallingford, UK. (This volume).

Vorosmarty, C. J. et al. (2010) Global threats to human water security and river biodiversity. Nature, 467, 555-561. doi:10.1038 /nature 09440.

Wang Hao, et al. (2013) China Water Risk Assessment Method. Social Sciences Academic Press, Beijing, China. 